\title{
PARENTAL AUTONOMY-SUPPORT AND PSYCHOLOGICAL CONTROL IN EATING DISORDER PATIENTS WITH AND WITHOUT BINGE-EATING/PURGING BEHAVIOR AND NON-SUICIDAL SELF-INJURY
}

\author{
LIES DEPESTELE \\ Psychiatric Hospital Alexianen Tienen, Belgium; University of Leuven, Belgium; \\ Ghent University, Belgium \\ BART SOENENS AND GILBERT MD LEMMENS \\ Ghent University, Belgium \\ EVA DIERCKX \\ Psychiatric Hospital Alexianen Tienen, Belgium; Vrije Universiteit Brussel, \\ Belgium
}

KATRIEN SCHOEVAERTS

Psychiatric Hospital Alexianen Tienen, Belgium

LAURENCE CLAES

University of Leuven, Belgium; University of Antwerp, Belgium

The current study examines whether autonomy-supportive and controlling parenting are related to the presence/absence of binge-eating/purging behavior and/ or non-suicidal self-injury in adolescents with an eating disorder (ED). Fifty-three ED patients completed validated questionnaires assessing perceived maternal and paternal autonomy-supportive and psychologically controlling parenting. A total

Address correspondence to Lies Depestele, Eating Disorders Unit, Psychiatric Hospital, Alexianen Tienen, Liefdestraat 10, 3300 Tienen, Belgium; E-mail: Lies. Depestele@fracarita.org 
of 53 mothers and 37 fathers also completed these questionnaires. All patients completed the Self-Injury Questionnaire-Treatment Related to assess non-suicidal self-injury (NSSI). Results showed that patients with binge-eating purging behaviors experienced more maternal psychological control compared to restrictive patients independently of the presence of NSSI. Paternal psychological control or autonomy support did not differ as a function of ED subtype and presence/ absence of NSSI. These results suggest that especially mothers of patients engaging in binge-eating/purging behaviors could benefit from family interventions that support parents in diminishing the use of psychological control.

Keywords: eating disorders, non-suicidal self-injury, psychological control, autonomy-support, parental style, self-determination theory

Research on the role of parenting style in the development and the course of eating disorders (EDs) has a long-standing tradition (Tetley, Moghaddam, Dawson, \& Rennoldson, 2014). Parental style can be characterized along several dimensions, one of which is defined by the extent to which parents support the autonomy development of their child (parental autonomy support) or the extent to which parents intrude upon their child's thoughts, feelings and behavior in a controlling way (parental psychological control; Barber, 1996; Grolnick \& Pomerantz, 2009).

One recent study demonstrated the beneficial effects of a perceived autonomy-supportive parental style on eating disorder patients' autonomous motivation for treatment, which predicts better treatment outcome (i.e., weight gain in patients with anorexia nervosa; Van der Kaap-Deeder et al., 2014). In contrast, several studies demonstrated associations between psychologically controlling parenting and the development of ED symptoms, showing that these associations are mediated by variables such as maladaptive perfectionism, distress, or self-competence (Goddard et al., 2013; Salafia, Gondoli, Corning, Bucchianeri, \& Godinez, 2009; Snoek, Engels, Janssens, \& van Strien, 2007; Soenens et al., 2008). Only one study has simultaneously examined autonomy-supportive and controlling parenting in relation to ED symptoms. Reilly, Stey, and Lapsley (2016) found, in a sample of undergraduate students, that psychologically controlling (but not autonomy-supportive) parenting was related to ED symptoms. These findings suggest that associations of controlling parenting with ED-relevant behaviors are more pronounced 
than associations of autonomy-supportive parenting, a possibility that will be revisited in the current study.

Although there is evidence linking autonomy-supportive and psychologically controlling parenting — at least indirectly-to ED symptoms, it has not been examined specifically whether these parenting variables are related to the presence of binge-eating / purging behaviors (BP) or non-suicidal self-injury (NSSI), which are known to increase the complexity of the ED problems (Claes \& Muehlenkamp, 2014). With regard to BP behaviors, higher levels of paternal overprotection (but not maternal overprotection) were found among bulimia nervosa (BN) patients compared with anorexia nervosa (AN) patients (Leung, Thomas, \& Waller, 2000). Soenens and colleagues (2008) found higher levels of paternal psychological control in BN patients compared to a control group. Further, the anorexia nervosa, restrictive type (AN-R) group was situated in between the $\mathrm{BN}$ and the control group and did not significantly differ from the BN group and the control group. However, other studies did not find any differences in parental style between $\mathrm{AN}$ and $\mathrm{BN}$ patients (Tereno, Soares, Martins, Celani, \& Sampaio, 2008).

Further, despite the high prevalence of NSSI in ED patients, very little research has focused on the relation between parenting and the presence/absence of NSSI in ED patients. One study showed that ED patients with NSSI perceived their fathers to be less caring and to use a more affectionless control style of parenting (i.e., less caring and more controlling) compared to patients without NSSI (Fujimori et al., 2011). Another study showed that ED patients engaging in NSSI reported higher levels of parental criticism than those without NSSI (Claes, Soenens, Vansteenkiste, \& Vandereycken, 2012), and felt more external pressure to change (Vansteenkiste, Claes, Soenens, \& Verstuyf, 2013). In community samples, preadolescents engaging in NSSI (but not their parents) reported higher levels of parental psychological control compared to preadolescents not engaging in NSSI (Baetens, Claes, Martin et al., 2014).

In sum, research suggests that parents may be more controlling and less autonomy-supportive when patients display BP behaviors and/or engage in NSSI. These associations are important to be examined as theory and research suggest that 
autonomy-suppressing and controlling parenting may serve to maintain or worsen ED symptoms (Ryan, Deci, \& Vansteenkiste, 2016; Strauss \& Ryan, 1987). Thus, adolescent patients and parents may get caught in a negative vicious circle of deteriorating symptoms and quality of interaction.

In this study, the hypothesized association between BP behavior and/or engagement in NSSI and the use of more controlling and less autonomy-supportive strategies by parents is reconsidered, thereby using maternal and paternal ratings of parenting and using multiple informants. The correspondence between adolescents' and parents' reports is often found to be modest, with parents providing a more positive picture than adolescents (Korelitz \& Garber, 2016; Sessa, Avenevoli, Steinberg, \& Morris, 2001), which raises the question whether the hypothesized association between ED-related behaviors and parental behavior exists only in the eye of the beholder (i.e., in the patients' own perspective), or whether it exists also when considered from the parents' perspective.

\section{METHOD}

\section{PARTICIPANTS}

This study included 53 female adolescents with an ED and one or both of their parents. In total 53 mother-daughter dyads and 37 father-daughter dyads were included. All patients were admitted to a specialized unit for the treatment of EDs. ${ }^{1}$ The mean age of the patients was 17.98 years ( $S D=2.45$, range: $14-25$ years). Demographic characteristics of the mothers and fathers are described in Table 1.

All patients were assessed by the psychiatrist of the unit using a clinical interview according to the DSM-IV criteria (American Psychiatric Association, 1994), supplemented with the Eating Disorder Evaluation Scale (EDES; Vandereycken, 1993). Of the 53 patients, $24(45.3 \%)$, were diagnosed as anorexia nervosa, restrictive type (AN-R), 13 patients (24.5\%) as anorexia binge-eating/ purging type (AN-BP), 8 patients $(15.1 \%)$ as bulimia nervosa 
TABLE 1. Demographic Characteristics of the Mothers $(N=53)$ and Fathers $(N=37)$

\begin{tabular}{|c|c|c|c|c|}
\hline & \multicolumn{2}{|c|}{ Mothers $(N=53)$} & \multicolumn{2}{|c|}{ Fathers $(N=37)$} \\
\hline & $M$ & $(S D)$ & $M$ & $(S D)$ \\
\hline \multirow[t]{2}{*}{ Age mean $(S D)$} & 47.93 & (3.65) & 49.13 & (3.93) \\
\hline & $\mathrm{N}$ & $(\%)$ & $\mathrm{N}$ & $(\%)$ \\
\hline \multicolumn{5}{|l|}{ Marital status } \\
\hline Married/living together & 40 & (75.4) & 36 & $(97.3)$ \\
\hline Living single & 6 & (11.3) & 1 & (2.7) \\
\hline Long distance relationship & 3 & (5.7) & 0 & $(0.0)$ \\
\hline Missing values & 4 & (7.5) & 0 & $(0.0)$ \\
\hline \multicolumn{5}{|l|}{ Employment } \\
\hline Paid employment & 45 & $(84.8)$ & 37 & $(100.0)$ \\
\hline Unemployed/homemaker/sick/retired & 4 & (7.5) & 0 & $(0.0)$ \\
\hline Missing values & 4 & (7.5) & 0 & $(0.0)$ \\
\hline
\end{tabular}

(BN) and $8(15.1 \%)$ as ED not otherwise specified (ED-NOS). For the purpose of this study, patients were clustered into two ED subgroups: 26 patients (49.1\%; 24 with AN-R and 2 with EDNOS) were diagnosed with restrictive behavior (ED-R) and 27 (50.9\%; 13 with AN-BP, 8 with BN, and 6 with ED-NOS) with BP behaviors (ED-BP).

Thirty-two patients $(60.4 \%)$ reported lifetime presence of at least one type of NSSI, whereas 21 patients (39.6\%) never engaged in NSSI. The presence of NSSI was significantly higher in BP patients $(74.1 \%)$ compared to restrictive ED patients $(46.2 \%)$ $\left(\chi_{(1)}^{2}=4.32, p<0.05\right)$.

Illness duration was significantly longer in patients with BP behavior than in restrictive patients and also longer in patients with NSSI than in patients without NSSI $(p<0.05)$. No significant age difference was found between the two ED subgroups nor between patients with and without NSSI (Table 2).

\section{PROCEDURE}

All patients, mothers, and fathers completed an online survey during the first 4 weeks of admission after having given a writ- 
TABLE 2. Clinical Characteristics of the ED-R and ED-BP Patients $(N=53)$

\begin{tabular}{lccccc}
\hline \multicolumn{5}{c}{$\begin{array}{c}\text { Restrictive group (ED-R) } \\
(\mathbf{N = 2 7 )}\end{array}$} & $\begin{array}{r}\text { Binge-eating/purging group (ED-BP) } \\
(\mathbf{N = 2 6 )}\end{array}$ \\
\hline \multirow{4}{*}{ Age } & $\boldsymbol{M}$ & $(\boldsymbol{S D})$ & $\boldsymbol{M}$ & $(\boldsymbol{S D})$ & $\boldsymbol{t}$-test \\
BMI & 17.65 & $(2.33)$ & 18.30 & $(2.57)$ & 0.95 \\
IIIness duration (years) & 15.06 & $(1.96)$ & 19.95 & $(6.29)$ & $3.85^{* *}$ \\
& 2.33 & $(1.69)$ & 3.76 & $(2.57)$ & $2.41^{*}$ \\
Lifetime presence of NSSI & $\boldsymbol{N}$ & $(\%)$ & $\boldsymbol{N}$ & $(\%)$ & $\chi_{(1)}^{2}$ \\
Scratching & 12 & $(46.6)$ & 20 & $(74.1)$ & $4.32^{*}$ \\
Biting & 6 & $(24)$ & 14 & $(51.9)$ & $4.25^{*}$ \\
Bruising & 3 & $(12)$ & 7 & $(25.9)$ & 1.62 \\
Cutting & 6 & $(24)$ & 6 & $(22.2)$ & 0.23 \\
Burning & 9 & $(36)$ & 16 & $(59.3)$ & 2.81 \\
\hline
\end{tabular}

Notes. ${ }^{*} p<.05 ;{ }^{* *} p<0.01$

ten informed consent. The study was approved by the Ethical Committee of the Hospital.

\section{MEASURES}

Parental psychological control was assessed with the Psychological Control Scale (PCS; Barber, 1996). In this study, only 7 of the 8 original items were used, since one item ("I am always trying to change the way my daughter is feeling or thinking about things"), diminished the internal consistency of the scale (in particular in the maternal ratings). Items were rated on 5-point Likert scales ranging from 1 (strongly disagree) to 5 (strongly agree). Cronbach's alpha values for this scale in this study across the 4 ratings (patient versus parent $\times$ mother versus father) varied between .60 and .92 .

Parental autonomy support was assessed with the 7-item Autonomy Support Scale, a subscale of the Perceptions of Parents Scale (POPS; Grolnick, Ryan, \& Deci, 1991; Dutch translation: Soenens et al., 2007). Participants provided separate ratings for perceived paternal and maternal parental style. In addition, both fathers and mothers completed the parent-versions of both 
questionnaires. Items were rated on 5-point Likert scales ranging from 1 (strongly disagree) to 5 (strongly agree). Cronbach's alpha values in this study across the 4 ratings varied between .74 and .87 .

All patients also completed the Self-Injury QuestionnaireTreatment Related (SIQ-TR; Claes \& Vandereycken, 2007), to assess the presence of five specific NSSI behaviors. A patient was assigned to the NSSI category when she answered "yes" to at least one type of NSSI during lifetime. The Cronbach's alpha coefficient of the SIQ-TR in the present study was 0.70 .

\section{DATA-ANALYSES}

To examine differences in parental style between restrictive and BP ED patients and between patients with or without NSSI and to examine whether these differences depend on the reporter (parent or patient), two Repeated Measures Analyses of Covariance (RM ANCOVA) were performed: one with the responses of 53 mother-daughter dyads and another with the responses of 37 father-daughter dyads. A RM ANCOVA was chosen to take into account the interdependency between the daughters' and mothers'/fathers' responses. The patients' and mothers'/fathers' scores on the Psychological Control Scale and the Autonomy Support Scale were used as dependent variables, informant (mothers vs. patients/fathers vs. patients), was modelled as a within-subjects factor and the presence/absence of BP behavior, the presence/absence of NSSI and their interaction (BP*NSSI) were used as independent variables. A significant association between age/illness and the outcome variables was found (Table 3). Since illness duration and age are positively correlated and since illness duration (but not age) differed significantly between the ED (i.e., with or without BP and with or without NSSI), illness duration will be included as a covariate.

All analyses were performed by means of SPSS version 22. A type I error of 0.05 was used throughout all the analyses. 


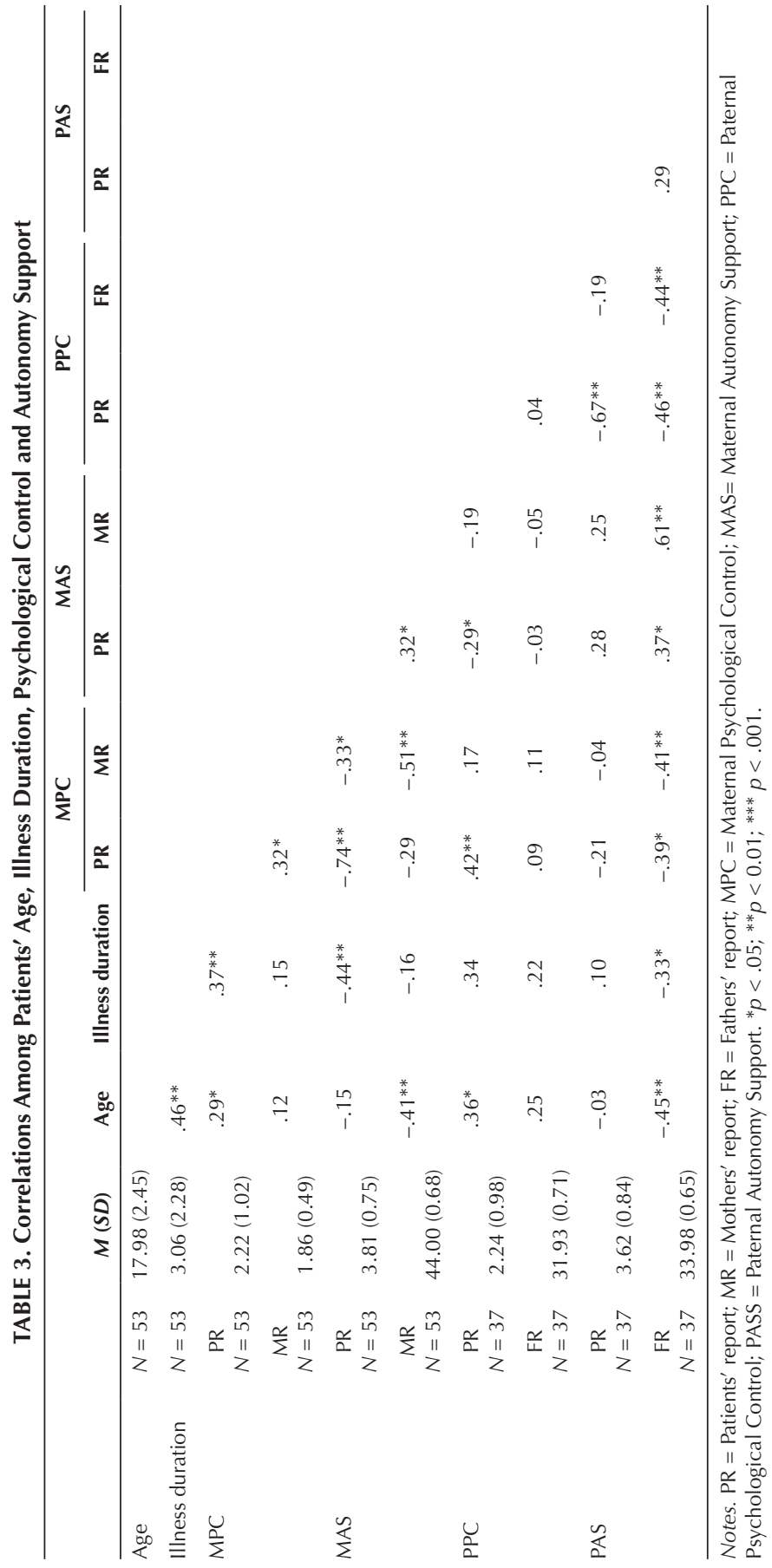


TABLE 4. Means (Standard Deviations) of Maternal Psychological Control and Maternal Autonomy Support in Function of ED Group,

Presence/Absence of NSSI and Informant $(N=53)$

\begin{tabular}{|c|c|c|c|c|c|c|}
\hline & \multicolumn{6}{|c|}{ Restrictive group (ED-R) } \\
\hline & \multicolumn{2}{|c|}{$\begin{array}{c}\text { No NSSI } \\
N=14\end{array}$} & \multicolumn{2}{|c|}{$\begin{array}{c}\text { NSSI } \\
N=12\end{array}$} & \multicolumn{2}{|c|}{$\begin{array}{c}\text { Total } \\
N=26\end{array}$} \\
\hline & $\begin{array}{c}\text { PR } \\
N=14\end{array}$ & $\begin{array}{c}M R \\
N=14\end{array}$ & $\begin{array}{c}\text { PR } \\
N=12\end{array}$ & $\begin{array}{c}M R \\
N=12\end{array}$ & $\begin{array}{c}\text { PR } \\
N=26\end{array}$ & $\begin{array}{c}M R \\
N=26\end{array}$ \\
\hline & $M(S D)$ & $M(S D)$ & $M(S D)$ & $M(S D)$ & $M(S D)$ & $M(S D)$ \\
\hline MPC & $1.94(0.71)$ & $1.67(0.45)$ & $1.72(0.70)$ & $1.77(0.31)$ & $1.84(0.70)$ & $1.72(0.39)$ \\
\hline \multirow[t]{5}{*}{ MAS } & $4.05(0.64)$ & $4.20(0.45)$ & $4.02(0.61)$ & $3.86(0.81)$ & $4.04(0.62)$ & $4.04(0.66)$ \\
\hline & \multicolumn{6}{|c|}{ Binge-eating / purging group (ED-BP) } \\
\hline & \multicolumn{2}{|c|}{$\begin{array}{c}\text { No NSSI } \\
N=7\end{array}$} & \multicolumn{2}{|c|}{$\begin{array}{c}\text { NSSI } \\
N=20\end{array}$} & \multicolumn{2}{|c|}{$\begin{array}{c}\text { Total } \\
N=27\end{array}$} \\
\hline & $\begin{array}{c}P R \\
N=7\end{array}$ & $\begin{array}{c}M R \\
N=7\end{array}$ & $\begin{array}{c}\text { PR } \\
N=20\end{array}$ & $\begin{array}{c}M R \\
N=20\end{array}$ & $\begin{array}{c}\text { PR } \\
N=27\end{array}$ & $\begin{array}{c}M R \\
N=27\end{array}$ \\
\hline & $M(S D)$ & $M(S D)$ & $M(S D)$ & $M(S D)$ & $M(S D)$ & $M(S D)$ \\
\hline MPC & $2.41(1.22)$ & $2.14(0.63)$ & $2.64(1.15)$ & $1.95(0.51)$ & $2.58(1.15)$ & $2.00(0.54)$ \\
\hline MAS & $3.67(0.86)$ & $3.67(0.91)$ & $3.56(0.81)$ & $4.06(0.62)$ & $3.59(0.81)$ & $3.96(0.71)$ \\
\hline
\end{tabular}

Notes. PR = Patients' report; $M R=$ Mothers' report; $M P C=$ Maternal Psychological Control;

MAS $=$ Maternal Autonomy Support. ${ }^{*} p<0.05$.

\section{RESULTS}

The RM ANCOVA with maternal autonomy support and maternal psychological control as dependent variables, informant (mothers vs. patients) as within-subjects factors, and NSSI and ED subgroup as independent variables showed a main effect of ED subtype, Wilks' $\lambda=0.88, F(2,47)=3.12, p=0.05$, (see Table 4). Subsequent univariate analyses showed elevated levels of psychological control $(p<0.05)$ in mothers of BP patients compared to those of restrictive patients. This effect was not moderated by type of reporter, indicating that it was robust across informants. Further, there was no main effect of the presence/absence of NSSI, Wilks' $\lambda=0.99, F(2,47)=0.17$, ns, nor a significant interaction between ED*NSSI subgroup, Wilks' $\lambda=0.94, F(2,47)$ $=1.37$, ns. No main effect of informant emerged, Wilks' $\lambda=0.99$, $F(2,47)=0.14$, ns. Further, no significant interactions between informant and NSSI/ED subgroups were found. Illness duration was a significant covariate, Wilks' $\lambda=0.88, F(2,47)=3.21, p=$ 0.05 : less maternal autonomy support $(p<0.05)$ and more maternal psychological control $(p=0.05)$ is reported in patients with 
TABLE 5. Means (Standard Deviations) of Paternal Psychological Control and Paternal Autonomy Support in Function of ED Group,

Presence/Absence of NSSI and Informant $(N=37)$

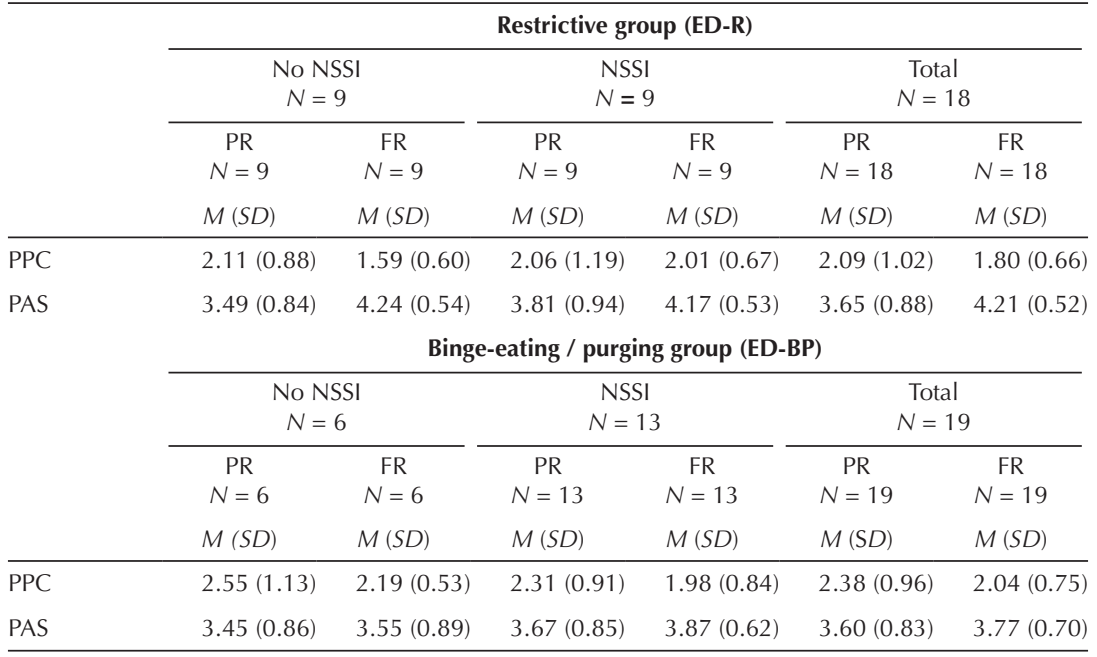

Notes. PR = Patients' reports; FR = Fathers' report; PPC = Paternal Psychological Control; PAS = Paternal Autonomy Support. $p<0.05$.

a longer illness duration. In sum, more maternal psychological control was reported in presence of BP behavior independently of the presence/absence of NSSI and independently of informant (Table 4).

A similar RM ANCOVA with paternal autonomy support and paternal psychological control as dependent variables showed no main effect of ED subgroup, Wilks' $\lambda=0.96, F(2,31)=0.68, n s$, no main effect of the presence/absence of NSSI, Wilks' $\lambda=0.95$, $F(2,31)=0.88, n s$, and no significant interaction between ED subgroup and the presence/absence of NSSI, Wilks' $\lambda=0.97, F(2,31)$ $=0.45$, ns. A main effect of informant emerged, Wilks' $\lambda=0.81$, $F(2,31)=3.66, p<0.05$. Univariate analyses showed that paternal autonomy support was rated significantly higher by fathers than by patients $(p<0.05)$. The patients' illness duration as a covariate was not significant, Wilks' $\lambda=0.99, F(2,31)=0.12$, $n$ s, (Table 5).

\section{DISCUSSION}

The main finding of this study is that mothers of ED-BP patients use more psychological control than mothers of restrictive ED 
patients independently of type of reporter. We discuss some of the possible underlying mechanisms of this association. First, as a rather visible and troubling signal of eating pathology, BP behavior may elicit parental feelings of powerlessness and incompetence (e.g., feeling unable to prevent their child from BP behavior), leading to an increase in psychologically controlling behavior toward a daughter with an ED (Pomerantz \& Eaton, 2001). Second, maternal psychological control may increase the likelihood of BP behavior. High levels of parental psychological control might predict deficits in emotion regulation that, in turn, might lead to an increased vulnerability for BP behavior in ED patients (McEwen \& Flouri, 2009; Salafia et al., 2009). Further, based on Self-Determination Theory (Deci \& Ryan, 2000), it has been argued and found that controlling parenting frustrates children's basic psychological needs for autonomy, competence, and relatedness (Soenens \& Vansteenkiste, 2010). Adolescents might develop BP behavior to cope with this need frustration (Verstuyf, Vansteenkiste, Soenens, Boone, \& Mouratidis, 2013). In a controlling environment an adolescent with ED will feel like she has no choice but to act in the way that is dictated by her parents. Then, $\mathrm{BP}$ behavior might become a strategy to solve the inner conflict between complying with her parents' request to eat and pursuing her personally endorsed goals (i.e., no gain weight; Botta \& Dumlao, 2002).

Interestingly, BP behavior was unrelated to maternal autonomy-support. This finding confirms that controlling parenting (as an expression of the "darker side" of parenting) is more relevant to predict maladaptive outcomes and psychopathology and that autonomy-supportive parenting (as an expression of the "brighter side" of parenting) is more relevant to predict adaptive developmental outcomes and well-being (Costa, Cuzzocrea, Gugliandolo, \& Larcan, 2016). Further, the association between parental psychological control and BP behavior was not found in the father-daughter dyads. This might be explained by the fact that mothers are more strongly involved in the nutritional aspects of parenting (e.g., preparing meals), might witness ED behavior of their daughters more frequently than fathers (Raenker et al., 2013), and consequently may get more affected by ED behavior than fathers (Depestele et al., 2016; Martín et al., 2011). However, 
this difference in findings might also be due to the smaller subsample size. Against our hypotheses, no association was found between parenting and the presence/absence of NSSI in ED patients. This is in contrast with previous findings in community samples that preadolescents engaging in NSSI (but not their parents) reported higher levels of parental psychological control compared to preadolescents not engaging in NSSI (Baetens, Claes, Martin et al., 2014). However, older adolescents and adolescents with a clinical diagnosis of ED might have developed more sophisticated methods of hiding their NSSI behaviors. As such, parents of older adolescents and of patients with a clinical diagnosis might not always be aware of their child's NSSI behavior. Thus, parental awareness of NSSI may be an important moderating factor (with NSSI eliciting psychologically controlling parenting only when parents know about the behavior) and a factor explaining discrepancies between studies (Baetens, Claes, Onghena et al., 2014).

Further, no significant differences were found between mothers' and patients' reports on psychological control and autonomy support. However, we found that paternal autonomy support was rated as significantly higher by fathers than by patients. This is in line with a general tendency for parents to rate their parenting style more positively than children (Korelitz \& Garber, 2016), and with our previous research showing that patients mostly differ with their fathers in their perception of family variables (Depestele et al., 2015).

Finally, this study showed that patients reported less maternal autonomy support and more psychological control as their illness duration was longer. This might indicate that the longer the illness takes, the more profoundly the parent-child relationship might be affected in a negative way, resulting in psychologically controlling parenting. However, it is also possible that patients who experience a higher level maternal psychological control are more vulnerable to develop more persistent ED symptoms.

This study has some limitations. The small sample size and the selection of inpatients only set limits to the generalizability of our results. Not all fathers filled out the questionnaires, which 
prevented us from directly comparing mothers' and fathers' parental style. Further, although the reliability for the Psychological Control Scale was generally good, it was low for one specific rating, that is, mothers' self-report $(\alpha=0.60)$. This is likely due to low rates of endorsement of some of the items especially by mothers. Finally, due to the cross-sectional design of the study, it is difficult to draw any conclusion about the causal mechanisms underlying the associations obtained. Longitudinal research in larger ED samples (inpatients/outpatients) with a control group with and without NSSI is needed to examine the direction of effects in associations of NSSI and BP behavior with parenting and to come to a deeper understanding of the underlying mechanisms in these associations.

This was the first study simultaneously investigating associations of BP behavior and/or NSSI with parenting in ED patients, including ratings of both mothers and fathers. The association between higher levels of maternal psychological control and $\mathrm{BP}$ behavior in ED patients might indicate that in these families special attention is needed for the mother-daughter dynamic. Mothers of ED-BP patients probably could benefit from family interventions that support parents in diminishing the use of psychological control to cope with ED symptoms in their child.

\section{REFERENCES}

American Psychiatric Association (1994). Diagnostic and statistical manual of mental disorders (4th ed.). Arlington, VA: American Psychiatric Publishing.

Baetens, I., Claes, L., Martin, G., Onghena, P., Grietens, H., Van Leeuwen, K., Wiersema, J. R., \& Griffith, J. W. (2014). Is non-suicidal self-injury associated with parenting and family factors? The Journal of Early Adolescence, 34, 387405.

Baetens, I., Claes, L., Onghena, P., Grietens, H., Van Leeuwen, K., Pieters, C., Wiersema, J. R., \& Griffith, J. W. (2014). Non-suicidal self-injury in adolescence: A longitudinal study of the relationship between NSSI, psychological distress and perceived parenting. Journal of Adolescence, 37, 817-826.

Barber, B. K. (1996). Parental psychological control: Revisiting a neglected construct. Child Development, 67, 3296-3319.

Botta, R. A., \& Dumlao, R. (2002). How do conflict and communication patterns between fathers and daughters contribute to or offset eating disorders? Health Communication, 14, 199-219. 
Claes, L., \& Muehlenkamp, J. (2014). Non-suicidal self-injury in eating disorders. New York: Springer.

Claes, L., Soenens, B., Vansteenkiste, M., \& Vandereycken, W. (2012). The scars of the inner critic: Perfectionism and non-suicidal self-injury in eating disorders. European Eating Disorders Review, 20, 196-202.

Claes, L., \& Vandereycken, W. (2007). Self-injurious behaviour: Differential diagnosis and functional differentiation. Comprehensive Psychiatry, 48, 137-144.

Costa, S., Cuzzocrea, F., Gugliandolo, M. C., \& Larcan, R. (2016). Associations between parental psychological control and autonomy support, and psychological outcomes in adolescents: The mediating role of need satisfaction and need frustration. Child Indicators Research, 9, 1059-1076.

Deci, E. L., \& Ryan, R. M. (2000). The "what" and "why" of goal pursuits: Human needs and the self-determination of behavior. Psychological Inquiry, 11, 227-268.

Depestele, L., Claes, L., Dierckx, E., Baetens, I., Schoevaerts, K., \& Lemmens, G. (2015). The role of non-suicidal self-injury and binge-eating/purging behaviour in family functioning in eating disorders. European Eating Disorders Review, 23, 413-416.

Depestele, L., Lemmens, G., Dierckx, E., Baetens, I., Schoevaerts, K., \& Claes L. (2016). The role of non-suicidal self-injury and Binge-eating-purging behaviour in the caregiving experience among mothers and fathers of adolescents with eating disorders. European Eating Disorders Review, 24, 257-260.

Fuijimori, A., Wada, Y., Yamashita, T., Choi, H., Nishizawa, S., Yamamoto, H., \& Fukui, K. (2011). Parental bonding in patients with eating disorders and selfinjurious behaviour. Psychiatry and Clinical Neurosciences, 65, 272-279.

Goddard, E., Salerno, L., Hibbs, R., Raenker, S., Naumann, U., Arcelus, J., . . . Treasure, J. (2013). Empirical examination of the interpersonal maintenance model of anorexia nervosa. International Journal of Eating Disorders, 46, 867-874.

Grolnick, W. S., \& Pomerantz, E. M. (2009). Issues and challenges in studying parental control: Toward a new conceptualization. Child Development Perspectives, 3, 165-170.

Grolnick, W. S., Ryan, R. M., \& Deci, E. L. (1991). Inner resources for school achievement: Motivational mediators of children's perceptions of their parents. Journal of Educational Psychology, 83, 508.

Korelitz, K. E., \& Garber, J. (2016). Congruence of parents' and children's perceptions of parenting: A meta-analysis. Journal of Youth and Adolescence, 45, 19731995.

Leung, N., Thomas, G., \& Waller, G. (2000). The relationship between parental bonding and core beliefs in anorexic and bulimic women. British Journal of Clinical Psychology, 39, 205-213.

Martín, J., Padierna, A., Aguirre, U., Quintana, J. M., Las Hayas, C., \& Muñoz, P. (2011). Quality of life among caregivers of patients with eating disorders. Quality of Life Research, 20, 1359-1369.

McEwen, C., \& Flouri, E. (2009). Fathers' parenting, adverse life events, and adolescents' emotional and eating disorder symptoms: The role of emotion regulation. European Child \& Adolescent Psychiatry, 18, 206-216. 
Pomerantz, E. M., \& Eaton, M. M. (2001). Maternal intrusive support in the academic context: Transactional socialization processes. Developmental Psychology, 37, 174-186.

Raenker, S., Hibbs, R., Goddard, E., Naumann, U., Arcelus, J., Ayton, A. . . Treasure, J. (2013). Caregiving and coping in carers of people with anorexia nervosa admitted for intensive hospital care. International Journal of Eating Disorders, 46, 346-354.

Reilly, E. E., Stey, P., \& Lapsley, D. K. (2016). A new look at the links between perceived parenting, socially-prescribed perfectionism, and disordered eating. Personality and Individual Differences, 88, 17-20.

Ryan, R. M., Deci, E. L., \& Vansteenkiste, M. (2016). Autonomy and autonomy disturbances in self-development and psychopathology: Research on motivation, attachment, and clinical process. In D. Cicchetti (Ed.), Developmental psychopathology (3rd ed., Vol. 1, pp. 385-438). New York: Wiley.

Salafia, E.H.B., Gondoli, D. M., Corning, A. F., Bucchianeri, M. M., \& Godinez, N. M. (2009). Longitudinal examination of maternal psychological control and adolescents' self-competence as predictors of bulimic symptoms among boys and girls. International Journal of Eating Disorders, 42, 422-428.

Sessa, F. M., Avenevoli, S., Steinberg, L., \& Morris, A. S. (2001). Correspondence among informants on parenting: Preschool children, mothers, and observers. Journal of Family Psychology, 15, 53-68.

Snoek, H. M., Engels, R.C.M.E., Janssens, J.M.A.M., \& van Strien, T. (2007). Parental behavior and adolescents' emotional eating. Appetite, 49, 223-230.

Soenens, B., \& Vansteenkiste, M. (2010). A theoretical upgrade of the concept of parental psychological control: Proposing new insights on the basis of selfdetermination theory. Developmental Review, 30, 74-99.

Soenens, B., Vansteenkiste, M., Lens, W., Luyckx, K., Goossens, L., Beyers, W., \& Ryan, R. M. (2007). Conceptualizing parental autonomy support: Adolescent perceptions of promotion of independence versus promotion of volitional functioning. Developmental Psychology, 43, 633.

Soenens, B., Vansteenkiste, M., Vandereycken, W., Luyten, P., Sierens, E., \& Goossens, L. (2008). Perceived parental psychological control and eating-disordered symptoms: Maladaptive perfectionism as a possible intervening variable. The Journal of Nervous and Mental Disease, 196, 144-152.

Strauss, J., \& Ryan, R. M. (1987). Autonomy disturbances in subtypes of anorexia nervosa. Journal of Abnormal Psychology, 96, 254-258.

Tereno, S., Soares, I., Martins, C., Celani, M., \& Sampaio, D. (2008). Attachment styles, memories of parental rearing and therapeutic bond: A study with eating disordered patients, their parents and therapists. European Eating Disorders Review, 16, 49-58.

Tetley, A., Moghaddam, N. G., Dawson, D. L., \& Rennoldson, M. (2014). Parental bonding and eating disorders: A systematic review. Eating Behaviors, 15, 49-59.

Vandereycken, W. (1993). The Eating Disorder Evaluation Scale (EDES). Eating Disorders, $1,115-122$. 
Van Der Kaap-Deeder, J., Vansteenkiste, M., Soenens, B., Verstuyf, J., Boone, L., \& Smets, J. (2014). Fostering self-endorsed motivation to change in patients with an eating disorder: The role of perceived autonomy support and psychological need satisfaction. International Journal of Eating Disorders, 47, 585600 .

Vansteenkiste, M., Claes, L., Soenens, B., \& Verstuyf, J. (2013). Motivational dynamics among eating-disordered patients with and without non-suicidal selfinjury: A Self-Determination Theory approach. European Eating Disorders Review, 21, 209-214.

Verstuyf, J., Vansteenkiste, M., Soenens, B., Boone, L., \& Mouratidis, A. (2013). Daily ups and downs in women's binge eating symptoms: The role of basic psychological needs, general self-control, and emotional eating. Journal of Social and Clinical Psychology, 32, 335-361. 